\title{
THE PRINCIPLES OF DEVELOPING A MANAGEMENT DECISION SUPPORT SYSTEM FOR SCIENTIFIC EMPLOYEES
}

\author{
Zarifa Jabrayilova \\ Institute of Information Technology \\ National Academy of Sciences of Azerbaijan \\ 9 B. Vahabzada str., Baku, Azerbaijan, AZ1141 \\ djabrailova_z@mail.ru
}

\begin{abstract}
Employees engaged in mental work have become the most valuable assets of any organization in the 21st century. The satisfaction of those involved in mental work requires the provision of objectivity and transparency in their decision-making. This, in turn, entails the development of scientifically motivated decision making mechanisms and scientific-methodological approaches to evaluate their performance based on innovative technologies.

The main goal of this article is in development of the scientific and methodological framework for the establishment of a decision support system to manage the employees engaged in mental work and operating in uncertainty. In this regard, initially, the question of evaluating the activities of scientific workers is examined, its characteristic features are determined, and the fuzzy relation model is proposed as a multi-criterion issue formed in uncertainty. Taking into consideration the hierarchical structure of the criteria that allows evaluating the activities of scientific workers, a phased solution method based on an additive aggregation method is proposed. In accordance with the methodology, a functional scheme of the decision support system to manage the scientific personnel is developed. The working principle of each block and the interaction of the blocks are described. The rules for the employees' management decisions are shown by referring to the knowledge production model.

Based on the proposed methodological approach, the implementation phases of the decision support system for the management of the scientific workers of the Institute of Information Technology of ANAS are described. To evaluate the employees' performance, the tools to collect initial information, evaluate the system of criteria, define their importance coefficients and mathematical descriptions are provided. Some results of the system software are presented. The opportunities of the system based on the proposed methodology to support enterprise mangers to make scientifically justified decisions are provided.
\end{abstract}

Keywords: researcher, activity assessment, uncertainty, fuzzy relation model, additive aggregation, staff evaluation.

DOI: $10.21303 / 2461-4262.2019 .00951$

\section{Introduction}

Objectives of human resource management (HRM) are the basis of personnel policy. The correct solution to these problems, making objective and transparency decisions on HRM allows the organization to achieve its global goals [1, 2]. In general, today the human resource management becomes the strategy of the company or firm. In this case, the funds invested in the development of human resources, transform into an investment, not expenditure [1]. The changes, occurred in the labor market, require major changes in the relationship with employees, in the policy of their recruitment, retention and motivation. In this regard, human resource management at the professional level has become a strong modern means used in HR. Fundamentally new attitude towards the personnel as valuable resource of the organization actualizes the importance of developing new conceptual approaches and technologies for HRM $[2,3]$. Therefore, in recent years, computer technology is increasingly used for the HRM problem solutions.

The success of the twenty-first century, the age of information society and knowledge-based economy, refer to the increasing productivity of mental activity and the employees engaged in mental activity. The valuable asset of any commercial or non-profit organization is its mental work forces and their productivity. The productivity of the employees engaged in the mental activity is determined by the following six factors $[4,5]$ :

1. A clear answer to the question: What is "the essence of the production task?", i. e. how the "result" of the activity of the relevant organization (firm, enterprise, field)is defined? 
2. Responsibility for the productivity depends of each employee himself/herself, that is, they are their own managers.

3. Uninterrupted innovative activity should be an integral part of the mental activity and must be included in the production task of any employee engaged in mental activity.

4. Employees engaged in mental activity always have to learn from and teach one another.

5. Productivity of employees engaged in mental activity is not measured quantitatively or quantitatively, i.e., its quality covers a broader scope and is defined by many parameters.

6. Finally, to increase the productivity of employees involved in mental activity, they need to be reviewed as "capital" rather than "expense" and should be treated accordingly. In this regard, employees should be encouraged to work in that organization and should regard it as the best option.

These factors represent the multi-dimensional, multi-criteria, and quantitative and qualitative character of the employees involved in mental activity. Depending on the fields of the organization, the productivity of its employees engaged in mental activity is characterized by different parameters. Increase in productivity primarily requires appropriate selection of these parameters and precise assessment of activity. Assessment of mental activity with the consideration of these aspects and requirements entails the objectiveness and transparency of the decisions made for the solution of the issues such as employees' satisfaction, promotion, rewarding, stimulation, deployment and redeployment, etc. All this requires the development of more innovative approaches to the evaluation of the activity of the employees involved in mental activity, and the development of decision mechanisms that meet the requirements set forth.

Thus, the aim of this article is in development of an intelligent decision support system for the management of the employees dealing with mental labor. To achieve this aim, the following issues are stated:

- to model a labor activity assessment of the employees dealing with mental labor;

- to develop a labor activity assessment technique;

- to implement an intelligent decision support system for the management of the employees referring to the results of labor activity assessment.

\section{Modeling of researchers' activity assessment}

Scientific employees, in particular, researchers who are professionally engaged in scientific and scientific-technical activities, are regarded as the resources of special importance in the industrialization of the country, the intellectual revival of the nation, and in the interstate competitiveness in economic, political and technological fields, and in enhancing the innovation capabilities of the state. Establishment and strengthening of the knowledge society and knowledge-based economy, ensuring its sustainable, dynamic and competitive development, and the realization of the prioritized role of science are determined by the scientific achievements [6].

Thus, the study of the problems related to the management of the employees engaged in scientific activity, the identification of the features characterizing their activities, and the objectiveness and transparency of the employees' management decisions require the development of the mechanisms for activity assessment. Objective and truthful assessment of the productivity of mental activity, which provides the professional progress of scientific employees and achieving their goals in accordance with prospective strategy, constitutes the basis for the personnel policy in this segment $[5,7,8]$.

As it is mentioned, when evaluating the researchers' performance, the direct assessment subject is activity, and its quantitative assessment becomes problematic.

The activity of scientific employees differs according to scientific areas (fundamental, applied and experimental research, etc.) and types (humanities, nature, medicine, social and technical sciences). This difference is particularly represented in the analysis of the objective and subjective conditions of scientific and technical activity and complicates the assessment of the performance of scientific employees.

As it is mentioned, the most important feature characterizing the activity of scientific employee is the fact that their achievements are difficult and sometimes impossible to be measured 
with certain quantities. Thus, sometimes, the results of activity are not revealed at once, but after some time, and even much later [4].

Therefore, the parameters selected to evaluate the activity of employees should ensure democracy, transparency and objectivity of the assessment system, and provide the same and fair attitude to all employees enabling the managerial decisions based on the evaluation results $[9,10]$.

The diversity of the activity of employees is determined by the use of quantitative and qualitative criteria in the assessment, by their usual hierarchic character and their relevance. Analysis and evaluation of the activity based on such criteria requires certain time. The changes and external influences during this period do not allow for exact depiction of the problem. The issue is realized in uncertain circumstances and becomes the problem of decision-making in a fuzzy environment [11-17].

Thus, the evaluation of the activity of scientific employees requires referring to the fuzzy apparatus taking into account the hierarchical and fuzzy nature of the criteria, and the linguistic uncertainties regarding the formalization of the expert knowledge. Such an expression of the problem ensures the problem to be solved by being reduced to the problem of fuzzy multicriteria optimization and ranking. Here, the optimization is not a matter of mathematical optimization, but a selection of the alternative options $[13,14]$.

Fuzzy multicriteria optimization techniques are based on the aggregation of an affiliation function by referring to the fuzzy relation model. According to the fuzzy relation model, $X=\left\{x_{1}, x_{2}, \ldots, x_{n}\right\}=\left\{x_{i}, i=\overline{1, n}\right\}$ and $K=\left\{k_{1}, k_{2}, \ldots, k_{m}\right\}=\left\{k_{j}, j=\overline{1, m}\right\}$ s a set of the alternatives, out of which the best one should be selected, whereas is a set of criteria characteristic to the alternatives ( $K$ is a summarizing criterion), then the correspondence of these alternatives with the criteria can be presented by a two-dimensional matrix. The element of this matrix is determined by the affiliation function, which represents the extent of correspondence of the alternative $x_{i}$ with the criterion $k_{j}: \phi_{k_{j}}\left(x_{i}\right): X \times K \rightarrow[0,1]$. Here, $\phi_{k_{j}}\left(x_{i}\right)$ represents the extent of correspondence of the alternative $x_{i}$ with the criterion $k_{j}[15]$.

\section{The technique for the assessment of researchers' activity based on the fuzzy relation model}

The key stages of the solution of the problem of activity assessment of scientific employees are as follows:

1) formation of the structural scheme of the evaluation system, namely, the alternatives: the list of employees, whose activity is evaluated, the evaluation criteria system, imposed restrictions and objectives;

2) selection of methods for the acquisition (selection of experts, expert evaluation, selection of quantitative and qualitative levels of criteria) and processing (mathematical representation of criteria, determination of relative importance coefficient of criterion) of initial information;

3) selection of a method that enables an integral evaluation of the results for the criteria out of certain evaluation set.

Stage 1 identifies the followings:

1) $X=\left\{x_{i}, i=\overline{1, n}\right\}$ is a set of alternatives, more precisely, the employees engaged in scientific-theoretical, scientific-practical, practical and educational activities in a research institution;

2) $K=\left\{K_{j}, j=\overline{1, m}\right\}$ is a set of criteria with different weight characteristic to the alternatives ( $K$-summarizing criterion);

3) each criterion $K_{j}, j=\overline{1, m}$ is determined based on the different weighted sub-criteria that can be evaluated, i. e., $K_{j}=\left\{k_{j t}, t=\overline{1, T}\right\}$.

Stage 2. A single quality measurement scale (SQMS) approach can be attributed to an expert evaluation of the mathematical description of the sub-criteria characterizing the activity. This approach:

a. selects SQMS representing the transition of linguistic values (for example, 3-level - "good", "normal", "weak"), which corresponds to the intensity level (3, 5, 7, 9 levels are available) of the quality indicator of our natural language and is defined within the interval [0,1], to the fuzzy numeral;

b. approves sub-criteria as linguistic variables, and divides them into intensity levels in accordance with SQMS, and adopts appropriate linguistic values and fuzzy numbers per level. 
To determine importance coefficients of the criteria, 10-score system uses the expert evaluation method or a pairwise comparison criterion [18].

This stage defines the following:

1) affiliation function of alternatives to the assessible alternatives $\left\{k_{j t}, t=\overline{1, T}, j=\overline{1, m}\right\}$ :

$$
\left\{\phi_{k_{j 1}}\left(x_{i}\right), \phi_{k_{j 2}}\left(x_{i}\right), \ldots, \phi_{k_{j T}}\left(x_{i}\right)\right\}=\left\{\phi_{k_{j t}}\left(x_{i}\right), t=\overline{1, T}, j=\overline{1, m}\right\}
$$

2) importance coefficient of the criteria, i. e.

$$
\left\{w_{1}, w_{2}, \ldots, w_{m}\right\}=\left\{w_{j}, j=\overline{1, m}\right\}
$$

and importance coefficient of the sub-criteria included in the same group:

$$
\left\{w_{j 1}, w_{j 2}, \ldots, w_{j T}\right\}=\left\{w_{j t}, t=\overline{1, T}, j=\overline{1, m}\right\}
$$

and the condition

$$
\sum_{t=1}^{T} w_{j t}=1
$$

is provided to the sub-criteria that characterizes the same criterion.

The goal is in obtaining a ranked list of employees based on the affiliation of the scientific employee to the summarizing criterion $K$, i. e., the determination of $\phi_{K}\left(x_{i}\right) \rightarrow[0,1]$. That is: $X: K \rightarrow X^{*}$, where $X^{*}$ is the adjusted list of employees.

Stage 3. The method proposed for the evaluation of activity of scientific employees requires an assessment of the alternatives, taking into account the hierarchical structure of the criteria and their diverse importance. In this regard, the additive aggregation method is referred and the problem is solved in the following sequence $[19,20]$ :

1. According to (1) and (3), the affiliation function of the alternative $x_{i}$ to $K_{j}$ is defined as:

$$
\phi_{K_{j}}\left(x_{i}\right)=\sum_{t=1}^{T} w_{j t} \phi_{k_{j t}}\left(x_{i}\right) .
$$

2. According to $\left\{\phi_{K_{j}}\left(x_{i}\right), j=\overline{1, m}\right\}$ and (2), the affiliation function of all alternatives $\mathrm{x}_{i}$, $\{i=\overline{1, n}\}$ to the summarizing criterion $K$ is defined:

$$
\phi_{K}\left(x_{i}\right)=\sum_{j=1}^{m} w_{j} \phi_{K_{j}}\left(x_{i}\right) .
$$

3. The alternative, the affiliation function to the summarizing criterion $K$ of which gains the maximum value: $\phi\left(x^{*}\right)=\max \left\{\phi_{K}\left(x_{i}\right), i=\overline{1, n}\right\}$.

Selected alternative is the "best" alternative out of $n$ number of alternatives, and ranked the first in the list of alternatives ranking for the value of their affiliation function to the summarizing criterion $K$.

\section{Functional blocks of researchers' performance assessment system}

As noted above, the precise assessment of activity of employees ensures the objectivity and transparency of their management decisions [10]. Based on the proposed technique, the functional scheme of decision support system for the assessment of the activity of scientific employees and their rewarding, promotion and re-deployment based on the evaluation results is illustrated in Fig. 1.

Interface ensures the communication between the system and the user. A user can select the following operating modes in the system via the interface: 
- submitting the initial information on activity assessment;

- evaluating the activity, obtaining results;

- submitting the rules that shape the knowledge base for appropriate decision support;

- making appropriate management decisions for each employee.

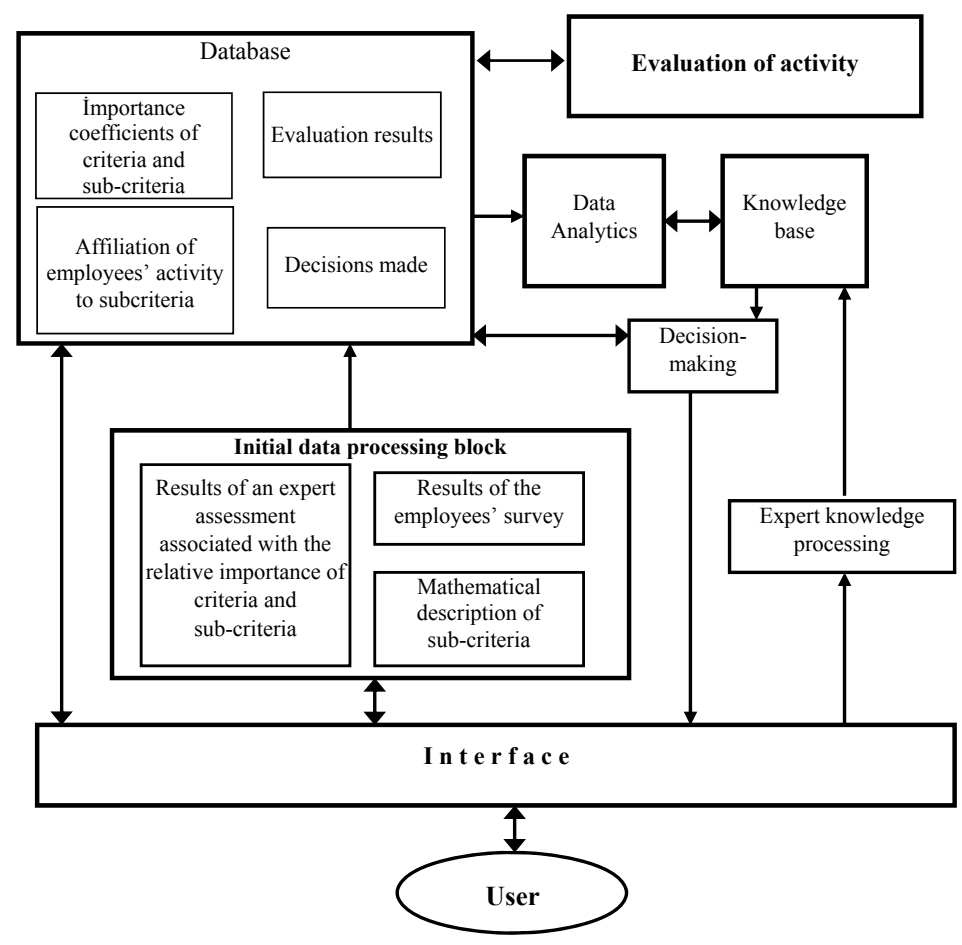

Fig. 1. Functional scheme of decision support system for the assessment of the activity of scientific employees

Initial information processing defines the importance coefficient of criteria and sub-criteria, and generates their mathematical formulation based on the correspondence of employees' activity to sub-criteria.

The mathematical representation of sub-criteria in this block is illustrated in Table $\mathbf{1}$ in accordance with the proposed technique. Here, using the 3-level of SQMS, a sequence of mathematical description of the sub-criteria "Participation in the implementation of research" of the criterion "Scientific-theoretical activity", which characterizes the activity of scientific employees.

Table 1

Mathematical description of the sub-criteria "Participation in the implementation of research" characterizing the criteria "Scientific-theoretical activity"

\begin{tabular}{|c|c|c|c|}
\hline $\begin{array}{l}\text { Linguistic variable - granulation of the sub-criteria } \\
\text { «Participation in the implementation of research» characterizing } \\
\text { the criteria «Scientific-theoretical activity }\end{array}$ & Linguistic value & $\begin{array}{l}\text { Fuzzy subset } \\
\text { within the } \\
\text { interval }[0,1]\end{array}$ & Fuzzy number \\
\hline a) takes an active part in scientific research; & good & {$[0,9 \div 1]$} & 0.98 \\
\hline b) takes a part in scientific research; & normal & {$[0,66 \div 0,89]$} & 0.70 \\
\hline c) takes part in scientific research partially. & weak & {$[0,40 \div 0,65]$} & 0.40 \\
\hline
\end{tabular}

The database $(D B)$ includes the essential data required for the assessment of employees' activity: the affiliation functions of each employee's activity to sub-criteria, the importance coefficients of criteria and sub-criteria, the final estimations of employees' activity (including the results 
of the periodic assessments), and the decisions related to rewarding, promotion or re-deployment of each employee.

Evaluation of activity implements a mechanism for evaluating employees' activity based on the proposed technique.

The sequence of the evaluation process in this block is described in the following tables in accordance with the proposed technique.

Table 2 builds a two-dimensional fuzzy relation matrix, which represents the degree of correspondence of each worker to the sub-criteria.

\section{Table 2}

The membership function of employees' activity to sub-criteria

\begin{tabular}{|c|c|c|c|c|c|c|c|}
\hline \multirow{3}{*}{ Alternatives } & \multicolumn{7}{|c|}{$K$} \\
\hline & \multicolumn{3}{|c|}{$K_{1}$} & \multirow[t]{2}{*}{$\ldots$} & \multicolumn{3}{|c|}{$K_{m}$} \\
\hline & $k_{11}$ & $\ldots$ & $k_{1 L}$ & & $k_{m 1}$ & $\ldots$ & $k_{m T}$ \\
\hline $\mathrm{x}_{1}$ & $\phi_{k_{11}}\left(x_{1}\right)$ & $\ldots$ & $\phi_{k_{1 L}}\left(x_{1}\right)$ & $\ldots$ & $\phi_{k_{m 1}}\left(x_{1}\right)$ & $\ldots$ & $\phi_{k_{m T}}\left(x_{1}\right)$ \\
\hline$\cdots$ & $\cdots$ & $\ldots$ & $\cdots$ & $\cdots$ & $\ldots$ & $\ldots$ & $\ldots$ \\
\hline$x_{i}$ & $\phi_{k_{11}}\left(x_{i}\right)$ & $\ldots$ & $\phi_{k L}\left(x_{i}\right)$ & $\ldots$ & $\phi_{k_{m 1}}\left(x_{i}\right)$ & $\ldots$ & $\phi_{k_{m T}}\left(x_{i}\right)$ \\
\hline$\ldots$ & $\cdots$ & $\ldots$ & $\cdots$ & $\ldots$ & $\cdots$ & $\ldots$ & $\ldots$ \\
\hline$x_{n}$ & $\phi_{k_{11}}\left(x_{n}\right)$ & $\ldots$ & $\phi_{k_{1 L}}\left(x_{n}\right)$ & $\ldots$ & $\phi_{k_{m 1}}\left(x_{n}\right)$ & $\ldots$ & $\phi_{k_{m T}}\left(x_{n}\right)$ \\
\hline
\end{tabular}

The next step is to calculate the affiliation function of the employees' activity to the subcriteria in DB based on formula (4) by using the relative importance coefficient of (Table 3 ).

Table 3

The membership function of alternatives to the generalized criterion $K$

\begin{tabular}{|c|c|c|c|c|c|}
\hline \multirow{2}{*}{ Alternatives } & \multicolumn{5}{|c|}{$\boldsymbol{K}$} \\
\hline & $K_{1}$ & $\cdots$ & $\boldsymbol{K}_{\boldsymbol{j}}$ & & $K_{m}$ \\
\hline$x_{1}$ & $\phi_{K_{1}}\left(x_{1}\right)$ & $\ldots$ & $\phi_{K_{j}}\left(x_{1}\right)$ & $\ldots$ & $\phi_{K_{m}}\left(x_{1}\right)$ \\
\hline$\ldots$ & $\ldots$ & $\ldots$ & $\ldots$ & $\ldots$ & $\ldots$ \\
\hline$x_{i}$ & $\phi_{K_{1}}\left(x_{i}\right)$ & $\ldots$ & $\phi_{K_{1}}\left(x_{i}\right)$ & $\ldots$ & $\phi_{K_{m}}\left(x_{i}\right)$ \\
\hline & $\ldots$ & $\ldots$ & $\ldots$ & $\ldots$ & $\ldots$ \\
\hline$x_{n}$ & $\phi_{K_{1}}\left(x_{n}\right)$ & $\ldots$ & $\phi_{K_{j}}\left(x_{n}\right)$ & $\ldots$ & $\phi_{K_{m}}\left(x_{n}\right)$ \\
\hline
\end{tabular}

Referring to the results obtained and the relative importance coefficients of the criteria in $\mathrm{DB}$, the final value of the employees' activity is found based on formula (5), and then the results are forwarded to DB.

An employee providing the condition $\phi_{K}\left(x^{*}\right)=\max \left\{\phi_{K}\left(x_{i}\right), i=\overline{1, n}\right\}$ ( $n$ is the number of employees) is the most progressive employee of the institute according to the value of his/her performance corresponding to the criterion $x^{*}$, and a list of employees ranked in a decreasing order is obtained similarly.

Data analytics (logical outcome) detects the facts ensuring the results obtained from the evaluation method (including the previous periodical evaluations), and providing the employees' management decisions referring to other data stored in DB.

Knowledge base consists of the rules representing the managerial decisions in accordance with the affiliation of the employees' activity to criteria (or sub-criteria) and summarizing criteri- 
on. The first part of the production rules, which are based on expert knowledge and described as "if ..., then ...", corresponds to the specific fact based on the values of the criterion (or summarizing criterion, sub-criteria) that characterizes the activity for a particular decision. Whereas the "result" represents the management decision appropriate to the same fact.

The rules for staff rewarding are based on the proposed limits related to the amount of the award. It should be noted that the amount of award to be presented to the employees corresponds to the linguistic values on 4 levels, as "very high, high, medium, low". In this case, the rules for awarding can be described as follows:

Rule 1. If $\phi\left(x_{i}\right) \in[0.9,1]$, then the employee may be awarded a "very high" award;

Rule 2. If $\phi\left(x_{i}\right) \in[0.75,0.9)$, then the employee may be awarded a "high" award;

Rule 3. If $\phi\left(x_{i}\right) \in[0,60,0.75)$, then the employee may be awarded a "medium" award;

Rule 4. If $\phi\left(x_{i}\right) \in[0.50,0.60)$, then the employee may be awarded a "low" award;

Rule 5. If $\phi\left(x_{i}\right) \in[0.30,0.50)$, then the employee is not awarded;

Rule 6. If $\phi\left(x_{i}\right) \in[0.00,0.30)$, then the employee must be reviewed.

To support decisions on Staff re-positioning, a profile of the department, where the employee is employed, i. e., the department dealing with scientific research, a department dealing with scientific-practical activities, a serving department (library, multi-media, consulting service, etc.) or education department, should be determined when the regulatory framework of rules base is formed.

Research department of the institute is conditionally denoted by Ss, the department dealing with scientific-practical activities - by Sp, the serving department - by Sx, and the education department - by St. In this case, the following rules may be used to support the re-positioning of employees:

Rule 1. If $\phi_{K_{1}}\left(x_{i}\right) \in[0.00,0,30]$ and $\phi_{K_{3}}\left(x_{i}\right) \geq 0,5$ and $x_{i} \in S_{s}$, then the re-positioning of this employee to the scientific-practical department can be reviewed;

Rule 2. If $\left(\phi_{K_{1}}\left(x_{i}\right) \in[0.00,0,30]\right.$ and $\phi_{k_{33}}\left(x_{i}\right) \geq 0,75$ and $\left.x_{i} \in S_{s}\right)$, then the re-positioning of this employee to the education department can be reviewed, and so forth.

Here, $\phi_{K_{1}}\left(x_{i}\right)$ is the affiliation function of the employee to the scientific-theoretical activity criteria, $\phi_{K_{3}}\left(x_{i}\right)$ - to the scientific-practical activity criteria, and $\phi_{k_{33}}\left(x_{i}\right) \geq 0,75$ - to the pedagogical activity criteria.

The formation and perfection of the knowledge base of the system based on the relevant rules is resolved within the framework of the relevant organizational norms, human resource management standards, and under the supervision of the Trade Union in accordance with the protection of the rights and reputations of the employees in the research institution [21, 22].

\section{Stages of implementing a decision support system for the management of scientific employees}

Based on the methodological approach, a system for the evaluation of the scientific workers' performance working at the Institute of Information Technology of ANAS is developed.

In this regard: formed:

1) a criteria system consisting of 6 criteria characterizing performance of employees is

$$
K=\left\{K_{m}, m=\overline{1,6}\right\}
$$

where $K$ - generalized criteria of labor activity; $K_{1}$ - scientific-theoretical activity; $K_{2}$ - scientificpractical activity; $K_{3}$ - practical activity; $K_{4}$ - supporting activity; $K_{5}-$ discipline; $K_{6}-$ criterion for increasing professional competence.

Each criterion included into the set of criteria is characterized by a large number of sub-criteria. For example, the sub-criteria characterizing the criterion of scientific-theoretical activity $\left(K_{1}\right)$ are:

- participation in scientific research $\left(k_{11}\right)$;

- reporting at the institute's workshops $\left(k_{12}\right)$;

- publishing scientific articles $\left(k_{13}\right)$;

- supervising doctoral and PhD students $\left(k_{14}\right)$;

- working with masters $\left(k_{15}\right)$; 
- writing books, brochures, monograph (taking into account scientific and labor capacity) $\left(k_{16}\right)$;

- reporting at conferences, symposiums and scientific meetings (taking into account levels) $\left(k_{17}\right)$;

- scientific expertise (writing references to scientific papers) $\left(k_{18}\right)$.

Thus, criteria for evaluating the performance of scientific employees are defined as the following subsets:

$$
\begin{gathered}
K_{1}=\left\{k_{11}, k_{12}, \ldots, k_{18}\right\}, \\
K_{2}=\left\{k_{21}, k_{22}, \ldots, k_{25}\right\}, \\
K_{3}=\left\{k_{31}, k_{32}, \ldots, k_{37}\right\}, \\
K_{4}=\left\{k_{41}, k_{42}, \ldots, k_{45}\right\}, \\
K_{5}=\left\{k_{51}, k_{52}\right\}, \\
K_{6}=\left\{k_{61}, k_{62}, \ldots, k_{67}\right\} .
\end{gathered}
$$

2) To define the relative importance coefficients of criteria and sub-criteria a 10-grade expert evaluation method is applied. In this regard, 7 tables are developed and submitted to the experts. One of these tables is designed to evaluate the six main criteria that characterize labor activity and the remaining six tables to evaluate the sub-criteria that characterize these criteria.

3) Three-level SQMS is applied for the mathematical description of the sub-criteria that characterize labor activity. The approach described in [20] is applied to determine the final fuzzy value based on the individual values defined by the members of an expert group consisting of 5 experts.

Table 4 presents a sequence of mathematical descriptions of the sub-criteria "Participation in the implementation of scientific research (SR)" of the criteria "scientific-theoretical activity" characterizing the labor activity of scientific workers.

\section{Table 4}

Mathematical descriptions of sub-criteria "Participation in the implementation of scientific research (SR)" characterizing the criteria "Scientific-theoretical activity"

\begin{tabular}{lccc}
\hline $\begin{array}{c}\text { Linguistic variable - gradation of sub-criteria «Participation in the } \\
\text { implementation of scientific research (SR)» characterizing } \\
\text { the criteria «scientific-theoretical activity» }\end{array}$ & $\begin{array}{c}\text { Linguistic } \\
\text { variable }\end{array}$ & $\begin{array}{c}\text { Fuzzy } \\
\text { sub-criteria in } \\
\text { interval }[\mathbf{0 , 1}]\end{array}$ & Fuzzy number \\
\hline a) Actively participates in the implementation of SR; & normal & {$[0,9 \div 1]$} & 0.98 \\
b) Participates in the implementation of SR; & poor & {$[0,40 \div 0,65]$} & 0.70 \\
c) Partly participates in the implementation of SR. & & 0.40
\end{tabular}

4) To collect initial information about the employees' performance, the "Employee Survey Questionnaire" is drawn up. The survey questionnaire describes the employee's first name, last name, department, activity criterion, and the sub-criteria that characterize these criteria, and the gradation of each of them.

Each employee fills in a questionnaire by specifying the gradation of the sub-criteria he/ she considers appropriate for his/her activity. Thus, he/she indirectly participates in the labor activity assessment process and solves the problem of "who evaluates an employee?" which is one of the most important methodological problems in the development of the evaluation system. This approach is called self-assessment and allows each employee to express honest and essential information about his/her labor activity. Another advantage of self-assessment is that it allows each employee to analyze himself/herself which encourages him/her to use own abilities and skills more efficiently. The information source provided to the "Employee Survey Questionnaire" approved by 
the head of the Institute and the head of the department is the primary information source for the evaluation system to be developed.

5) Relevant software and a computer system for the evaluation of scientific workers' performance are developed.

The information is submitted to the database of the system on the following forms:

1) list of departments of the institute;

2) list of employees by departments;

3) list of criteria characterizing the labor activity;

4) list of sub-criteria characterizing the labor activity;

5) list of gradations of sub-criteria and fuzzy values of each gradation in the interval $[0,1]$;

6) list of experts;

7) 10-grade expert estimates to determine the importance coefficients of criteria;

8) 10-grade expert estimates to determine the importance coefficients of sub-criteria;

9) survey questionnaire data;

10) relative importance coefficients of criteria;

11) relative importance coefficients of sub-criteria.

Based on the submitted initial data, the value of each employee's labor activity is determined, and this information is stored in the database.

At the next stage, a list of employees ranked based on the values of their labor activity is developed. It should be noted that the ranked list is possible to be developed on the institute (Fig. 2), on separate departments (Fig. 3) and also on criteria (and sub-criteria).

DB review enables the review and update of departments, data based on surveys based on surveys, chapters, employees, criteria, sub-criteria, grades, experts, expert estimates of criteria, expert estimates of sub-criteria, and review and update of data based on Survey Questionnaire.

The data can be submitted to the database based on the questionnaire by selecting the "Employee's Performance Evaluation" mode, and the input data can be modified and deleted.

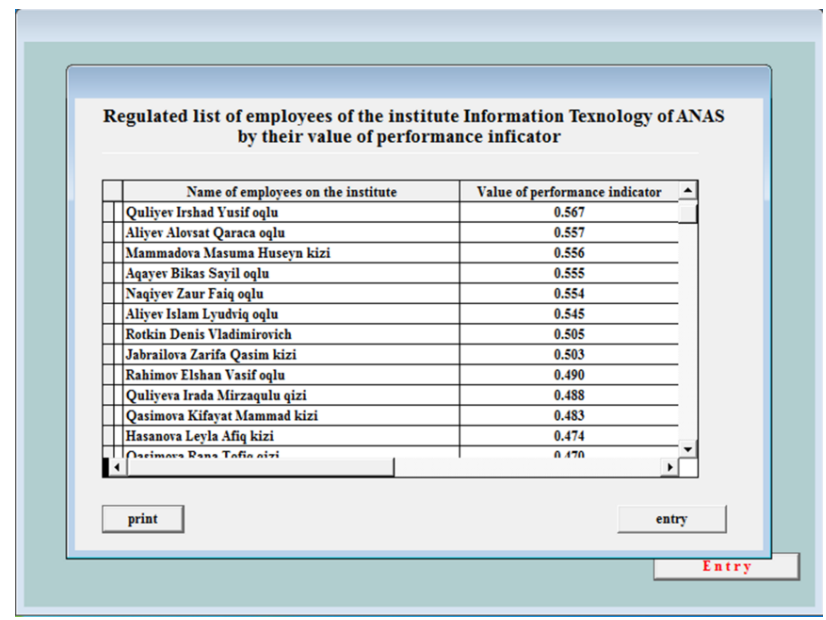

Fig. 2. Value of performance indicator of employees on the Institute (regulated list)

The survey data of each employee can be viewed based on the form.

The following three different calculation operations are performed in the system calculation block, and the obtained results are stored in the database:

- Referring to the results of 10 -grade evaluation of the criteria of 17 experts stored in DB, their relative importance coefficients are calculated, and the results are stored in DB;

- Referring to the results of 10-grade evaluation of the sub-criteria of 17 experts stored in $\mathrm{DB}$, their relative importance coefficients are calculated, and the results are stored in DVB;

- Based on the information on the employee's labor activity submitted to the DB based on the survey questionnaire, "Calculation of the value of the labor activity" operation is performed in the calculation block, and the results are stored in DB. 


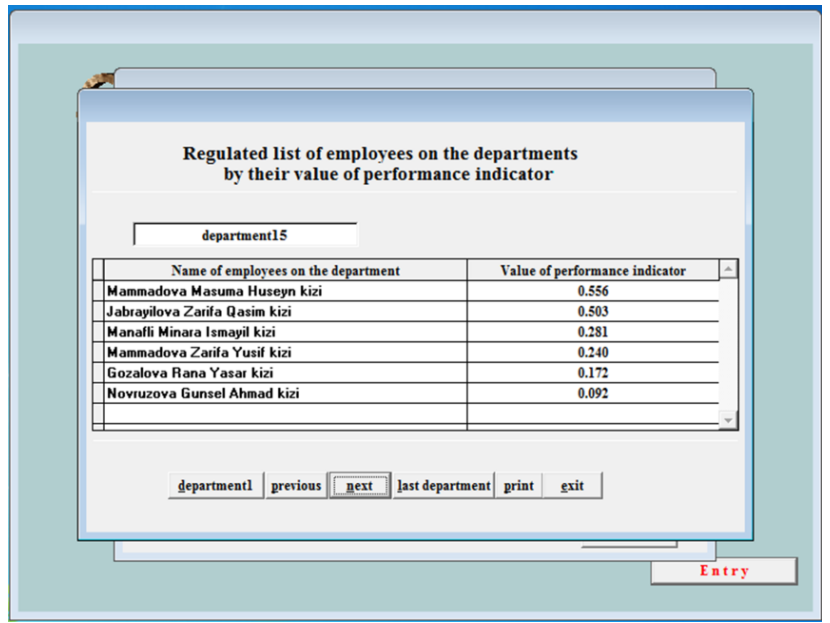

Fig. 3. Value of performance indicator of employees on departments (regulated list)

At this stage, the sequence of the data processing and the final evaluation of the labor activity of employees are executed on the following algorithm.

The fuzzy values corresponding to the gradations of the sub-criteria specified in accordance with the "Employee Survey Questionnaire" are selected from the certain table and represented in a new table in the 2-dimensional fuzzy relation matrix in front of the name of the corresponding employee.

The value mentioned refers to the extent to which the relevant employee corresponds to that sub-criteria (Table 5).

Table 5

Membership function of the employees' performance to the sub-criteria

\begin{tabular}{|c|c|c|c|c|c|c|c|c|c|c|}
\hline \multirow{3}{*}{ No. } & \multirow{3}{*}{ List of employees } & \multirow{3}{*}{$\begin{array}{l}\text { Notation } \\
\text { keys }\end{array}$} & \multicolumn{8}{|c|}{$K$} \\
\hline & & & \multicolumn{4}{|c|}{$K_{1}$} & \multicolumn{2}{|l|}{$\cdots$} & \multicolumn{2}{|l|}{$K_{6}$} \\
\hline & & & $k_{11}$ & $k_{12}$ & $\cdots$ & $k_{18}$ & $\cdots$ & $k_{61}$ & $\cdots$ & $k_{67}$ \\
\hline 1 & Abbasova M. Z. & $x_{1}$ & $\phi_{k_{11}}\left(x_{1}\right)$ & $\phi_{k_{12}}\left(x_{1}\right)$ & $\ldots$ & $\phi_{k_{18}}\left(x_{1}\right)$ & $\ldots$ & $\phi_{k_{61}}\left(x_{1}\right)$ & $\ldots$ & $\phi_{k_{67}}\left(x_{1}\right)$ \\
\hline \multirow[t]{2}{*}{2} & Bayramov N. L. & $x_{2}$ & $\phi_{k_{11}}\left(x_{2}\right)$ & $\phi_{k_{12}}\left(x_{2}\right)$ & $\cdots$ & $\phi_{k_{18}}\left(x_{2}\right)$ & $\cdots$ & $\phi_{k_{61}}\left(x_{2}\right)$ & $\ldots$ & $\phi_{k_{67}}\left(x_{2}\right)$ \\
\hline & $\cdots$ & $\cdots$ & $\cdots$ & $\cdots$ & $\cdots$ & $\cdots$ & $\cdots$ & $\cdots$ & $\cdots$ & \\
\hline N. & Aliyeva L. H. & $x_{n}$ & $\phi_{k_{11}}\left(x_{n}\right)$ & $\phi_{k_{12}}\left(x_{n}\right)$ & $\ldots$ & $\phi_{k_{18}}\left(x_{n}\right)$ & $\cdots$ & $\phi_{k_{61}}\left(x_{n}\right)$ & $\ldots$ & $\phi_{k_{67}}\left(x_{n}\right)$ \\
\hline
\end{tabular}

The next step is to calculate the membership function of the employee's performance based on the formula (4) by using the relative importance coefficients of the sub-criteria in DB (Table 6).

Table 6

Membership function of the employee's performance to the criteria

\begin{tabular}{|c|c|c|c|c|c|c|c|c|}
\hline \multirow{2}{*}{ No. } & \multirow{2}{*}{ List of employees } & \multirow{2}{*}{$\begin{array}{l}\text { Notation } \\
\text { keys }\end{array}$} & \multicolumn{6}{|c|}{$K$} \\
\hline & & & $K_{1}$ & $K_{2}$ & $K_{3}$ & $K_{4}$ & $K_{5}$ & $K_{6}$ \\
\hline 1 & Abbasova M. Z. & $x_{1}$ & $\phi_{K_{1}}\left(x_{1}\right)$ & $\phi_{K_{2}}\left(x_{1}\right)$ & $\phi_{K_{3}}\left(x_{1}\right)$ & $\phi_{K_{4}}\left(x_{1}\right)$ & $\phi_{K_{5}}\left(x_{1}\right)$ & $\phi_{K_{6}}\left(x_{1}\right)$ \\
\hline \multirow[t]{2}{*}{2} & Bayramov N. L. & $x_{2}$ & $\phi_{K_{1}}\left(x_{2}\right)$ & $\phi_{K_{2}}\left(x_{2}\right)$ & $\phi_{K_{3}}\left(x_{2}\right)$ & $\phi_{K_{4}}\left(x_{2}\right)$ & $\phi_{K_{5}}\left(x_{2}\right)$ & $\phi_{K_{6}}\left(x_{2}\right)$ \\
\hline & $\ldots$ & $\ldots$ & $\ldots$ & $\ldots$ & $\ldots$ & $\ldots$ & $\ldots$ & $\ldots$ \\
\hline $\mathrm{N}$. & Aliyeva L. H. & $x_{n}$ & $\phi_{K_{1}}\left(x_{n}\right)$ & $\phi_{K_{2}}\left(x_{n}\right)$ & $\phi_{K_{3}}\left(x_{n}\right)$ & $\phi_{K_{4}}\left(x_{n}\right)$ & $\phi_{K_{5}}\left(x_{n}\right)$ & $\phi_{K_{6}}\left(x_{n}\right)$ \\
\hline
\end{tabular}


Based on the results obtained and the relative importance coefficients of the criteria in DB, the final value of the employees' labor activity is found based on the formula (5), and the results are uploaded to on the DB.

The employee ensuring the condition $\phi_{K}\left(x^{*}\right)=\max \left\{\phi_{K}\left(x_{i}\right), i=\overline{1, n}\right\}$ (n is the number of employees) in accordance with the alternative $\mathrm{x}^{*}$ is the most advanced employee at the institute, and in this way, the list of employees' performance ranking is obtained.

\section{Results and Discussion}

Solution of the development of the decision support system for the management of scientific employees and the evaluation of their labor activity decisions was implemented in three stages. At the first stage, the scientific-theoretical basis of the system to be developed was created. It was shown that the work of employees engaged in scientific activity is determined by a great number of criteria. These criteria are often qualitative, indefinite and fuzzy. This feature requires referring to the expert knowledge and to the linguistic expressions of our natural language as the measurement metrics for the evaluation of labor activity. Thus, the issue is characterized by a multi-criterion assessment problem formed in a fuzzy environment, and a fuzzy relation model is proposed for its solution. The criterion that characterizes the work of employees involved in scientific activities are hierarchic and their importance (both criteria and their sub criteria) are diverse. Thus, taking into account this, additive aggregation-based evaluation technique was proposed. The definition of the relative importance coefficients of input data, that is criteria (and their sub-criteria), and mathematical description methods of criteria are proposed. Proposed methodological approach:

- evaluates the labor activity of employees engaged in scientific activity univocally taking into account all indicators characterizing their activity and importance of these indicators;

- ensures objective and transparent management decisions and employees' satisfaction by fairly evaluating their labor activity.

At the second stage, the evaluation based on the proposed technique and referring to the evaluation results, the principles of projecting the management decision support system are performed. Functioning principles of the system, the working principles of its blocks and their interaction are shown. The system capabilities are as follows:

- univocally evaluates and ranks the outcome of each employee's labor activity for each sub-criterion, criterion and generalization criterion (labor activity value);

- identifies the most advanced (or passive) employee by each department (laboratory, group, etc.);

- identifies the most advanced (or passive) department (laboratory, group, etc.) by the institute (research center, organization etc.);

- identifies the most advanced (or passive) employee at the institute.

Referring to the assessment results, processing of employees' management decisions took place in the system knowledge base. Processing of employees' management decisions based on the knowledge production model was described in the examples of the issues regarding the awarding, re-recruitment and judgment of employees. And relevant rules constituting the knowledge base were developed.

At the third stage, the implementation phases of the decision support system for the management of scientific employees were given. This experiment was presented as an example of the evaluation system of the scientific employees' activity of the Institute of Information Technology of ANAS. In this regard, followings were implemented:

- a system of criteria characterizing the labor activity of employees was formed;

- relative importance coefficients of criteria and sub-criteria were determined;

- a mathematical description of sub-criteria characterizing the labor activity was presented;

- self-assessment method was used to obtain initial information about the employees' activity;

- a relevant software product was developed based on the proposed evaluation technique. 
As a result of implementing the periodic assessment (for example, semi-annual), the system can designate the dynamics of each employee for a particular criterion (or overall activity dynamics). This is, of course, very valuable information in managing employees.

The scientific and functional principles of the decision support system can also be used for other issues of human resource management (e. g. recruitment) that require intellectual support.

Thus, proposed scientific-methodological approach can be used not only to evaluate the scientific employees, but also to improve the management decisions and the evaluation of performance of other employees. These employees may work for government and commercial organizations, enterprises and offices. The use of such a system may assist the decision makers, managers, and other specialists in relevant fields dealing with employees' management.

The proposed approach requires deep and systematic study of the human resources, and the consideration of all criteria and sub-criteria characterizing their labor activity. On the other hand, inclusion or exclusion of any criterion (or sub-criterion) causes substantial changes in the implementation phase of the system. It may change the importance of others and cause for making amendments in the survey questionnaire for initial data collection. All this entails making proper changes to the software product, as well. One of the challenges of the system difficult is related to building a knowledge base, the acquisition of knowledge of analysts, and establishing decision-making rules.

\section{Conclusion}

Scientifically justified decisions regarding the management of scientific employees is crucial. Improvement of this process necessitates the introduction of intelligent technology. In this article, the scientific-theoretical and functional principles of developing an intelligent decision support system for the management of scientific employees were developed. To achieve this result, the followings were implemented:

- characteristics of the assessment of activity of scientific employees was defined, and fuzzy relation model as a multi-criteria ranking problem formed in an uncertain environment was proposed;

- problem solution technique based on the additive aggregation method was developed, taking into account the hierarchical structure of criteria and diversity of their importance;

- architectural principles and functional structure of the decision support system for employees' management were developed by referring to the evaluation results;

- results of the specific product generated in a certain environment by referring to the proposed scientific and functional principles were described. The decision support system for employees' management was implemented in stages.

\section{References}

[1] Mathis, R. L., Jackon, J. H., Valentine, S. R. (2014). Human Resource Management. Cengage Learning, 696.

[2] Mammadova, M. H., Jabrayilova, Z. Q., Mammadzada, F. R. (2016). Fuzzy Multi-scenario Approach to Decision-Making Support in Human Resource Management. Studies in Fuzziness and Soft Computing, 342, 19-36. doi: http://doi.org/10.1007/978-3319-32229-2_3

[3] Mammadova, M. H., Jabrayilova, Z. G. (2018). Fuzzy multi-criteria method to support group decision making in human resource management. Studies in Fuzziness and Soft Computing, 361, 209-222. doi: http://doi.org/10.1007/978-3-319-75408-6_17

[4] Drucker, P. F. (1999). Knowledge-Worker Productivity: The Biggest Challenge. California Management Review, 41 (2), $79-94$. doi:http://doi.org/10.2307/41165987

[5] Taylor, F. U. (1991). The Principles of scientific management. Moscow. Available at: http://gtmarket.ru/laboratory/basis/3631

[6] Law of the Republic of Azerbaijan on Science (09.08.2016). Available at: https://president.az/articles/20785

[7] Zlotnitsky, V. E. (2008). Factors of effective management of human resources of organization. Moscow, 190. Available at:www.dissercat.com/content/faktory-effektivnogo-upravleniya-chelovecheskimi-resursami-organizatsii

[8] Mammadova, M., Jabrayilova, Z. (2014). Application of Fuzzy Optimization Method in Decision-Making for Personnel Selection. Intelligent Control and Automation, 5 (4), 190-204. doi: http://doi.org/10.4236/ica.2014.54021 
[9] Odegov, Yu. G., Abdurakhmanov, K. Kh., Kotova, L. R. (2011). Evaluation of the effectiveness of personnel work: a methodological approach. Moscow: Publishing House AlfaPress, 752.

[10] Zaynetdinova, I. F. (2016). Evaluation of the employees' activities of the organization. Yekaterinburg: University Pub. House, 120.

[11] Zadeh, L. A. (1965). Fuzzy sets. Information and Control, 8 (3), 338-353. doi: http://doi.org/10.1016/s0019-9958(65)90241-x

[12] Zadeh, L. A. (1976). The concept of a linguistic variable and its application to approximate decision-making. Moscow: Mir, 168.

[13] Larichev, O. I. (2002). Theory and methods of decision-making, including the Chronicle of events in the Magic countries. Moscow: Logos, 392.

[14] Miconi, S. V. (2009). Multi-criteria selection based on a finite set of alternatives. Saint Petersburg: Publishing House Lan, 272.

[15] Mammadova, M. H. (1997). Decision-making based on knowledge bases with a fuzzy relational structure. Baku: Elm, 296.

[16] Bellman, R. E., Zadeh, L. A. (1970). Decision-Making in a Fuzzy Environment. Management Science, 17 (4), $141-164$. doi:http://doi.org/10.1287/mnsc.17.4.b141

[17] Mammadova, M. H., Jabrayilova, Z. G. (2018). Decision-Making Support in Human Resource Management Based on Multi-Objective Optimization. TWMS Journal of Pure and Applied Mathematics, 9 (1), 52-72.

[18] Mammadova, M. H., Djabrailova, Z. G., Nobari, S. M. (2010). Use of information about the importance of the criteria in the solution of personnel management problems. Problems of Cybermetics and Informatics. Baku, 83-86.

[19] Neumann, J. V., Morgenstern, O. (2007). Theory of games and economic behavior. One of Princeton University presses, Notable Centenary Titles, 776.

[20] Mammadova, M., Jabrayilova, Z. (2018). Methodological approach to the human resource management in virtual organizations. EUREKA: Physics and Engineering, 3, 3-11. doi: http://doi.org/10.21303/2461-4262.2018.00642

[21] Human resource core standards and checklist. HR Collaborative, 29. Available at: http://www.hrndgov.org/image/cache/ hr-checklist.pdf

[22] Public Sector Standards in Human Resource Management. Effective on and from 21 February 2011. Government of western Australia. Available at:https://publicsector.wa.gov.au/sites/default/files/documents/hrm_standards_3.pdf 